\title{
Familiarity and Unfamiliarity Factor: A Variable in the Cognition of Proverbs
}

\author{
Sukdeb Goswami \\ Department of Language and Literature, Utkal University of Culture, Bhubaneswar, Odisa, India
}

Email address:

sukdeb99@gmail.com

\section{To cite this article:}

Sukdeb Goswami. Familiarity and Unfamiliarity Factor: A Variable in the Cognition of Proverbs. English Language, Literature \& Culture. Vol. 4, No. 3, 2019, pp. 78-82. doi: 10.11648/j.ellc.20190403.13

Received: May 22, 2019; Accepted: July 23, 2019; Published: September 25, 2019

\begin{abstract}
Proverbs are a very common linguistic tool that provides a mechanism for understanding the general in terms of the specific. Their usage reveals the state of mind and mutual cognitive environment of the discourse participants in a linguistic exchange. The interpretation of a proverb involves a mapping process leading the hearer to search for a correspondence between the literal statement and its meaning within a context (Gibbs 1994). My paper aims at studying how familiarity and unfamiliarity factor of a proverb acts as a variable in the cognition of proverbs. It will examine how familiar proverbs are understood in a non-literal fashion more quickly than unfamiliar proverbs. For example, 'a rolling stone gathers no moss' will use less processing effort than a comparatively less familiar proverb like 'the used key is always bright' andit will expose how ultimately greater cognitive benefits are achieved from its processing. Once the proverb is confirmed as a fixed conceptual frame, the literal and non-literal senses equally integrate into an emerging meaning structure. It will also observe how expressions of these underlying conceptual relationships in the form of verbal metaphors quickly become a part of the culture's stock truismsand folk wisdom and how 'conceptual integration' and 'frame shifting' also depend on the familiarity and unfamiliarity of a proverb.
\end{abstract}

Keywords: Proverbs, Mutual Cognitive Environment, Conceptual Integration, Frame Shifting, Cultural Fields of Meaning etc

\section{Introduction}

Almost in every linguistic community there is an existence of some short rhythmic expressions called "proverbs" through which ethnic experiences are simply conveyed. A proverb contains wisdom, truth, morals and traditional views of a community in a metaphorical, fixed and memorizable form that is handed down from generation to generation [9]. Their usage reveals the state of mind, attitudes, and mutual cognitive environment etc of the discourse participants in a linguistic exchange. There is an episodic contribution or allusion to the creation of all proverbs. For example, the much familiar proverb "A stitch in time saves nine" has an etymological origin in the practice of "mending" a small "tear" in cloth before it becomes a larger one. It may have more than one possible meaning like:

a. A little effort expanded sooner to fix a small problem prevents it from becoming a larger problem requiring more effort to fix later. b. A little preparation can eliminate the need for repair later.

c. A timely effort can prevent larger problems.

Another instance of proverb "Ignorance is Bliss" owes its origin to Thomas Grey's poem "Ode on a Distant Prospect of Eton College" (1972) in the line "Where ignorance is bliss, 'tis folly to be wise". Its possible meanings may be:

a. Lack of knowledge results in happiness.

b. It is more comfortable not to know certain things.

Now I quote another proverb of Armenian origin that is found in small dialogic form:

"They asked wine, 'Have you built or destroyed more?'

It said, 'I do not know of building, of destroying I know a lot'."

In many cases it is very difficult to assign paternity of a proverb because same proverb may be found in different linguistic communities. Proverbs may have different grammatical structures:

Imperative/negative ------ Do not beat a dead horse. 
Imperative/affirmative ------ Look before you leap.

Parallel phrase -----Garbage in, Garbage out.

Rhetorical questions ----- Is the Pope Catholic?

Declarative sentence ----- Birds of a feather flock together. [https://en.m.wikipedia.org]

In many cases, proverbs become very familiar within a linguistic community and they are used in elliptical forms by quoting just a fraction. For example, "A rolling stone gathers no moss" is used as "A rolling stone" or "All is fair in love and war" is used as "All is fair".

The purpose of this study is to show how the processing efforts necessary for the cognition of a culturally familiar proverb differ from an unfamiliar proverb. The process of mutual manifestation of the literal statement of a proverb and its metaphorical or ironical meaning a specific context is largely dependent on this familiarity and unfamiliarity factor. To achieve this goal, the author will work on the following research question:

How does the cognition of a familiar proverb differ from an unfamiliar proverb?

\section{A Pragmatic Perspective of Proverbs}

Since proverbs contain diverse stylistic and pragmatic potentialities, they perform various perlocutionary acts that may be persuasive, encouraging, allusive, ironic, sarcastic, threatening, critical and so on. Hence, proverbs have the capacity to constitute speech acts that are socially accepted formulations of convictions, norms, values etc particular to a specific culture and era. This polyfunctionality of a proverb can only be found through a context and situation based interpretative analysis. If a speech act is perceived as an intention-driven or goal-oriented linguistic act, then proverbs are expressions of speech in concrete communicative situation. From Gricean perspective, there is an obvious flouting of the 'maxim of relevance' and 'quality'. For example, in the proverb "Faults are thick, while Love is thin', both 'faults' and 'love' are abstract concepts and hence they may not have 'thickness' or 'thinness' of concrete objects as described. However the figurative meaning goes beyond the literal meaning. Hence, here is also an obvious violation of Grice's co-operative principle between interlocutors and it achieves a particular perlocutionary effect.

From relevance theory perspective, the communicative event performed by a proverb also modifies the physical environment of the hearer and at the same time create representations similar to the one of the hearer. In Sperber and Wilson's definition of relevance, "an assumption is relevant in a context if and only if it has some contextual effect in that context". Proverbs also create some contextual effects in a necessary condition for the sake of relevance [15].

\section{Cognition of Proverbs}

Conceptual metaphor and metonymy are the two basic cognitive models that can account for much proverbial imagery [6]. For example in the metaphor "Health is Wealth" there is a conceptual metaphor and at the same time there is also a metonymic relation in the form of 'container for content'. Lakoff and Turner proposed that proverb comprehension involves the activation of a set of interpretativeprocedures that is subsequently termed as "The Great Chain Metaphor" (GCM). This theory uses four 'cognitive tools' to interpret proverbs in context [5].

i. "Generic is Specific" metaphor says that a generic metaphor is distinct from the common conceptual metaphors like 'Love is a Journey'. It allows proverb interpreters to use their knowledge about the specific scenario coded in the proverb in understanding many analogical situations when share generic level structure. For example, the proverb "One swallow does not make a summer" would demand specific knowledge about summer in specific geographical situations.

ii. There is a set of beliefs in specific cultural scenario in this "Great Chain of Being". It forms our understanding of ourselves and the world we live.

iii. The second tool mentioned above couples with the third part of the system. It says that our practical knowledge about "the nature of things" allows us to form theories about how the world works. The Great Chain ranks entities on a hierarchy in such a way that each entity in the chain possesses all the salient characteristics of the entities. The basic Great Chain is defined by attributes and behavior arranged in a hierarchy:

Humans---- higher order attributes and behavior

Animals ----- instinctual attributes and behavior

Plants------ biological attributes and behavior

Complex objects ---- structural attributes and functional behavior

Natural physical things ----- natural physical attributes and naturalphysical behavior [5]

iv. "The principle of verbal economy" says that while referring to an entity at a particular level in the hierarchy mentioned, the speaker must be referring to its highest order properties unless there is other information which precludes such an inference. Once we recognize proverbs, we know that they apply to human affairs [5].

But the Great Chain Metaphor model is not only complicated but also restrictive. It is complicated because the discourse context determines what units of a linguistic expression refer to and how they are interpreted. It is restrictive because discourse contexts allow proverbs to apply to other than just human affairs or to animal contexts (e.g. 'barking dog seldom bites'). The thing that occurs is that rather than attending to the specific principle that proverbs apply to human affairs, we simply apply the proverb scenario directly to immediate discourse context to develop the target interpretation. 


\section{Categorization: The Universal Aspect of Proverb Use}

All literal and figurative proverbs involve a universal categorization process. The scenario linguistically coded in the proverb acts as the categorizing structure that sanctions novel target events. This categorization process becomes effective when there is some analogy between the categorizing unit and the target structure or the actual situation. This similarity may range from almost complete identity (categorization by elaboration) to relative difference (categorization by extension) [7]. This 'categorization by extension' is the Cognitive Grammar that has analogy with "Generic is Specific" metaphor because it simultaneously accounts for categorization by extension and categorization by elaboration. For example, in the proverb 'One swallow does not make a summer' the metaphorical relation involves two distinct conceptual domains. In terms of categorization, the sanctioning structure is the conventional scenario coded in the proverb and the structure that is categorized is the analogical situation in the context. Hence there is a universal aspect of proverb interpretation as the contextual meaning of proverbs.

\section{Nature of Cognition: Both Metaphoric and Metonymic}

Though Lakoff defines proverbs as metaphoric in nature, ample metonymic elements also are found in proverbs [5]. Hence both in metaphoric and metonymic elements of proverbs we find a mapping relation either from a source domain to a target domain or from a target domain to a source domain. Metaphors can be used predicatively and metonymies can be used referentially. Hence there is no exact boundary between metaphoric and metonymic character of a proverb. The only difference that is visible is that metonymic mappings are domain-internal i.e. they hold a domain inclusion relationship. On the other hand, metaphors involve a domain external mappings i.e. mappings takes place across domains. Thus the relationship between two "Idealized Cognitive models" 'specific' and 'generic' in cognition of proverbs are in a 'stand-for-relationship'[8]. Therefore, instead of the 'generic for specific' metaphor, we may also have 'specific for generic' metonymic mapping. Hence, proverbs sometimes consist of 'source-in-target' metonymy involving domain specific expansion. As for instance, in the proverb "While at Rome, be a Roman", we have a metaphorical mapping that preserves the generic level structure. In this case, 'the Great Chain Metaphor' interacts with one basic metaphor "To go with the wind". At the same time there is another interaction with a metonymy of the 'source-in-target' kind', the Specific for Generic' one that involves a domain expansion like "Behave the way as deserved". This metonymy structure is a mental space to make the mapping from a specific to any generic situation that will be the source domain or part of the metaphor. Here are two input spaces: one is created by the metonymy and the other is derived from the specific situation to which the metonymy applies.

But the source-target metonymy in proverbs does not provide all the elements of conceptual structure needed to create a generic space that permits the metaphoric mapping. It merely highlights what is relevant to understand such metaphoric mapping. The generic space is built upon a different basis from the input space created by metonymy. It develops just one of the correspondences. In this way, the generic structure that shares such properties to make the relation between domains possible is taken from source and from the target domains of the metaphor as a whole, from all the correspondences. As Ruiz de Mendoza observes: "Metaphorical mappings preserve the generic level structure of the source domain in a way consistent with the inherent structure of the target domain" [8]. So, all contextual effects motivated by a metaphoric mapping will preserve the generic-level structure of the source domain and of any other input space involved in a way consistent with the inherent structure of the target domain. In this way, we have the convergence of the Generic is Specific metaphor. Hence "Rome" appears in a metonymic form of "a particular condition/space".

\section{Cultural Specificity in the Cognition of Proverbs}

The specific imagery behind the proverb's linguistic form is mostly culture specific. The assumption that proverbs are public representations of culture can be viewed from point of view of any language. Cultural facts depending on oral transmission are conditioned by local factors as well as by more general cognitive or motivational dispositions [14]. If we come across new speech community, we find new values, norms, institutions, and artifacts that influence the culture/thinking of that community. Consequently, proverbs as content of cultural representations and practices must be stable enough in a speech community for their performance and understanding by the members of a specific speech community [14]. Interpretative generalizations become determining factors in cross-cultural situations. It means that an interpretation of a phenomenon in a culture can be generalized in other cultures also because there may be existence of similar values, notions etc [13]. Though there are superficial variations, living kind classification exhibits strong commonalities across cultures in a manner that suggests the presence of a domain specific cognitive module. Limitation that we face here is "a gain in generality means a loss in faithfulness". Hence the generalizations are decontextualized and they refer to different local ideas, not fitting in some contexts [13].

\section{Nature of Contextualization of Familiar and Less Familiar Proverbs}

The idea of 'mutual manifestness' propounds that shared 
facts and assumptions manifest to speaker and hearer during the conversation. When it happens, the cognitive environment of both interlocutors intersects and they share a mutual cognitive environment. When a speaker uses a proverb, he/she actually make manifest a set of stereotypical assumptions to the hearer. Even though the discourse participants never share their total cognitive environment, the speaker expects the hearer to recognize this set of assumptions he/she is trying to make mutually manifest. When a speaker intends to use a familiar proverb he/she also intends to make manifest a set of stereotypical assumptions shared with the hearer. But with less familiar proverbs, this set of stereotypical assumptions is more difficult to achieve because "the more complex assumptions get, the less likely they are actually to be made"'[15]. Therefore, when a speaker uses a familiar proverb, he/she assumes that the hearer would build a set of correct assumptions avoiding misunderstandings because mutual manifestness demands a shared cognitive environment between the speaker and the hearer.

Hence there is universality in conceptual architecture and it operates behind the shared conceptual level of proverbs. The English proverb "Might is right" and its Bengali counterpart "Jor jar muluk tar" (trans. the powerful enjoy the power) may be related to the conception of "The Survival of the Fittest" in a given context. In a separate context it may mean that only the mighty persons can enjoy authoritative power. "The Great Chain Metaphor" applies to our overall knowledge of everything in the Great Chain ranging from human beings to inanimate objects. The schemata that characterize our knowledge about people are separate from the schemata that characterize our knowledge about physical objects. This common structure defines new conceptual categories in which the 'human' and the 'non-human' are seen as instances of same things. But this is very much culture specific. For example, here is a common conceptual architecture between:

a. A drowning man catches at a straw.

b. Where there is life, there is hope.

Now, if we try to make a mapping ofthe conceptual metaphor "Life is hope", we can see that The Great Chain Metaphor applies to the specific level schema evoked by the lexical properties in the following way:

a. Life mainly relates to human life.

b. The Nature of Things theory selects the attributes of "Life is hope".

c. 'The Maxim of Quality' selects the highest attributes and behaviorthat is relevant at each level.

Sometimes there is a problem of contextualization of a proverb. The assumptions we make about contextual meaning of a proverb may be affected by 'lexical polysemy'. Let us take the familiar proverb:

"A rolling stone gathers no moss".

For the Scottish, 'ROLLING' is positive and 'MOSS' is negative.

Hence it means "Moving all the time is efficient".

For the British, "ROLLING" is negative and "MOSS" is positive.

Hence the same proverb is used to mean differently: "Moving all the time is inefficient". Hence, such meanings are not context-dependent because the participants did not interpret the proverb online in real communicative situation. Such underlying conceptual relationships in the form of verbal metaphors become a part of the culture's stocktrueism and folk wisdom.

\section{Conclusion}

From the above discussion it may be concluded that familiar proverbs are processed much like "memes". But processing of an unfamiliar proverb involves 'extended cognition'. The interpreter's beyond-the-brain body has a vital causal and constitutive role in such cognitive processing. Even the unfamiliar proverbs are more contextdependent than familiar proverbs. Familiar proverbs generally carry with them a shared intentionality of usage, though it is culture specific. Hence factors that control the effective circulation of a proverb are its 'reproductive fitness' and 'epistemology of representation'. To get a detailed mapping of activation of conceptual frames and their shifting in the cognition of proverbs a further research is necessary. A cross-cultural view will certainly yield a better result.

\section{References}

[1] Coulson, S. (2001) Semantic Leaps: Frame Shifting and Conceptual Blending in Meaning Construction. Cambridge University Press, Cambridge.

[2] Coulson, S. and Matlock, T, (2001) 'Metaphor and the Space Structuring Model', Metaphor and Symbol, 16, (3\&4): 295-316.

[3] Gibbs, RW. (1994b) The Poetics of Mind: Figurative Thought, Language and Understanding (Cambridge university Press).

[4] Grice, P. (1991) 'Studies in the Way of Words', Harvard University press, London.

[5] Lakoff, G. and Turner, M. (1989) More Than Cool Reason: A Field Guide to Poetic Metaphor (Chicago University Press).

[6] Lakoff, G. and Johnson, M. (1980) Metaphors We Live By. Chicago University Press.

[7] Langacker, W. Ronald, (1987) Foundations of Cognitive Grammar; Stanford University press.

[8] Mendoza, R. de (1998), "On the Nature of Blending as a Cognitive Phenomenon" (Journal of Pragmatics, Vol. 30; P259-274).

[9] Mieder, Wolfgang (1993) "Proverbs are never out of Season: Popular wisdom and Modern Age" (Publisher: Peter Lang. Inc.).

[10] Mieder, Wilfgang (2004) Proverbs: A Handbook. Greenwood: Folklore Handbooks. United States.

[11] Oxford Learner's Dictionary (2015) Oxford University Press. Link: http://www.oxfordlearnersdictionaries.com/definition/english/ proverb?q=proverb. 
[12] Ritchie, L. D. (2006), Context and Connection in Metaphor (Palgrave Macmillan).

[13] Sperber, D. (1996), Explaining Culture: A Naturalistic Approach (London; Blackwell).

[14] Sperber, D. and Hirschfeld, L. (2007) Culture and Modularity; in 'The Innate Mind: Culture and Cognition. Oxford University Press.

[15] Sperber, D and Wilson, D. (1986; 1995) Relevance, Communication and Cognition (HarvardUniversity Press).

[16] https://en.m.wikipedia.org/wiki/proverb.

\section{Biography}

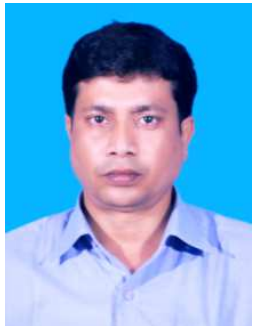

Sukdeb Goswami has been teaching English Language and Literature for more than eighteen years. Presently he is a research scholar at Utkal University of Culture, India. His research interests include mainly Pragmatic stylistics and Cognitive Poetics. He has attended and presented papers in many International conferences of Language and Literature and has a number of publications in renowned Journals in India and abroad. 